\title{
Effects of Mixing Temperature and Wood Powder Size on Mechanical Properties of Wood Plastic Recycled Composite*
}

\author{
Tsunehisa MIKI**, Hiroyuki SUGIMOTO**, Keisuke KOJIRO**, \\ Kozo KANAYAMA** and Ken YAMAMOTO*** \\ ** National Institute of Advanced Industrial Science and Technology (AIST) \\ 2266-98, Anagahora, Shimoshidami, Moriyama-ku, Nagoya, Aichi, Japan \\ E-mail:tsune-miki@aist.go.jp \\ *** Hiroshima Prefectural Technology Research Institute \\ 168-1, Toukaichi-tyo, Miyoshi-shi, Hiroshima, Japan
}

\begin{abstract}
In this study, wood (cedar) powder ranging from $53 \mu \mathrm{m}$ to $1 \mathrm{~mm}$ sizes, recycled polypropylene (PP) / polyethylene (PE) and acid-modified PP as a compatibilization agent were used to produce a wood-plastic recycled composite (WPRC). For discussing the effects of the wood powder sizes on the mechanical properties of the WPRC, a mixing process of the wood powder and the plastics in a constant wood content of $50 \%$ weight was firstly performed by a mixing machine controlled temperature and rotation of mixing blade. And then, to obtain WPRC panels the wood and plastics mixtures were compressed in a mould under a constant pressure and a temperature for a certain holding time. WPRC specimens for mechanical tests were cut from the WPRC panels, and a tensile strength and a size-stability were acquired. The results show that the successful mixing process runs above $180^{\circ} \mathrm{C}$, where the mixing torque required compounding keeps constant or slightly increases. The tensile strength of the WPRC increases when the smaller size of wood powder is used for wood/plastic compound under successful mixing conditions. It is shown from thickness change rate of specimens that mixing temperature of wood/plastic compound affects a size stability of the WPRC.
\end{abstract}

Key words: Wood Plastic Recycled Composite (WPRC), Mixing, Compound, Compatibilization, Durability

\section{Introduction}

Since woods are sustainable materials and keep fixing atmospheric carbon dioxide as their solid components during their uses, wood based materials can promise a good future from the view points of environmental problems associated with the global warming. Furthermore they will be able to save underground resources by reducing oil consumption when wood based materials alternate the other industrial materials such as plastics and metals.

In the North America, a wood based material has been applied for industrial materials such as a wood plastic composite (WPC). Such materials are mainly used as building materials for decking, window frame (sash), and wainscot panel, and the US market of WPCs have been increasing rapidly in recent two decades. In Europe, the market of WPCs 
is slowly taking off, and there are attempts to apply WPCs for automotive parts. Technical standards are being developed for WPC in EU $(1,2)$.

In Japan, WPCs have been firstly applied for indoor applications in the beginning of 1990. After that, by developing their formations and processing they can be used for outdoor applications such as a decking in 1997. Nowadays, Japan market of WPCs, especially public building applications, has been increased from 2000 around favored by "eco-materials". For developing WPCs with lower cost, techniques applying high wood content and uses of recycled plastic have been focused on, and some products of WPC actually contain recycled plastic. These WPCs, in which recycled plastics are used for raw materials, are called as wood plastic recycled composites (WPRCs). To facilitate applications and product share of WPRCs Japanese Industrial Standard (JIS A 5741) was formulated in 2006 (3). After that, many kinds of studies treating properties of WPRCs have been performed (4, 5 and 6$)$. To improve the mechanical properties of WPRCs chemical modifications of wood and plastics as well as coupling agents have been conducted. By using such modification techniques, interfacial bonding among wood and plastics can be strong due to improved compatibility among the polar hydrophilic wood and the non-polar hydrophobic plastics (7). However most of those good outcomes can be obtained in specific conditions, in which completely compounding of wood and plastics could be achieved or small wood fiber only is used. For practical processing techniques of WPRCs, conditions of compounding and wood powder size are important because these conditions are variable for row materials. However, there are few studies concerned with the effects of wood powder size and mixing conditions on the properties of WPRCs. Attaining such information will lead to the promotion of WPRCs uses.

In this study, to investigate the effects of wood powder size and mixing conditions such as temperature on the properties of a WPRC, the WPRC panels were prepared using mixtures of a sawdust wood powder ranging from 53 to $1000 \mu \mathrm{m}$ and recycled polypropylene (PP)/ polyethylene (PE) with acid-modified PP (AMPP), of which four mixing temperatures for four size-classified wood powder were subjected to study. And then, the mechanical properties of the WPRC such as a bulk density, a tensile strength and a size-stability were experimentally measured.

\section{Experimental}

\subsection{Materials}

A sawdust wood powder (cedar) without any addictives obtained from a building company was classified by four sizes, namely $53-150 \mu \mathrm{m}, 150-300 \mu \mathrm{m}, 300-500 \mu \mathrm{m}$ and $500-1000 \mu \mathrm{m}$. These powders are oven-dried to almost moisture content of $0 \%$ before a mixing process. In WPC productions, around $300 \mu \mathrm{m}$ wood powder is often used in Japan.

Recycled plastics of polypropylene (PP)/ polyethylene (PE) were obtained by a company, which are derived from food packaging containers. Fig. 1 shows thermal behavior of the recycled plastics measured by a differential scanning calorimeter (DSC). Two endothermic peaks are seen, which come from melting points of PE and PP. By considering a mixing process of these plastics with the wood powders, ambient temperature of plastics should be set as low as $163^{\circ} \mathrm{C}$.

As a compatibilizer, an acid-modified polypropylene (AMPP) was used, and this is commercialized as "u-mex" by Sanyo Chemical Industries Ltd. 


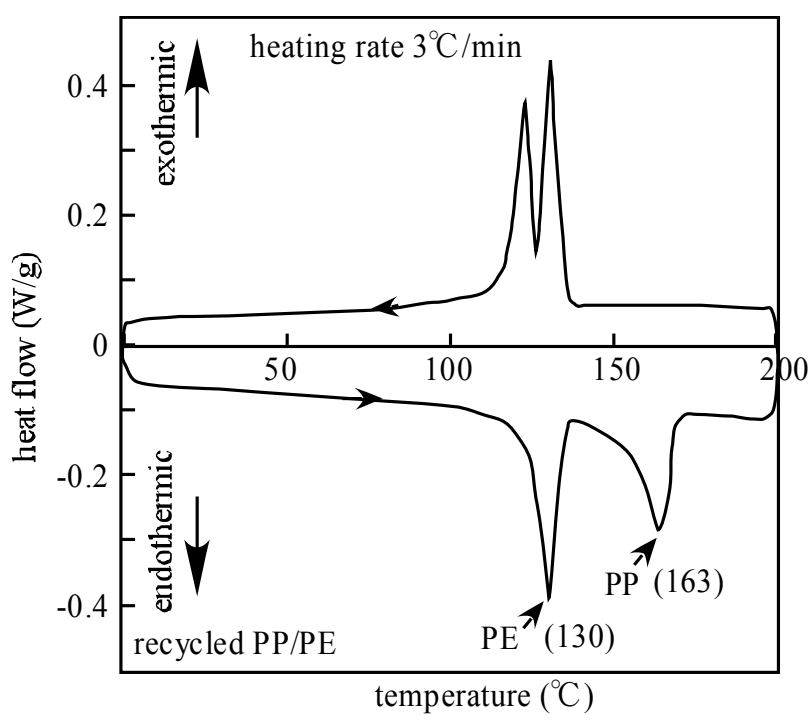

Fig. 1 Thermal behavior of recycled PP/PE analyzed by differential scanning calorimeter

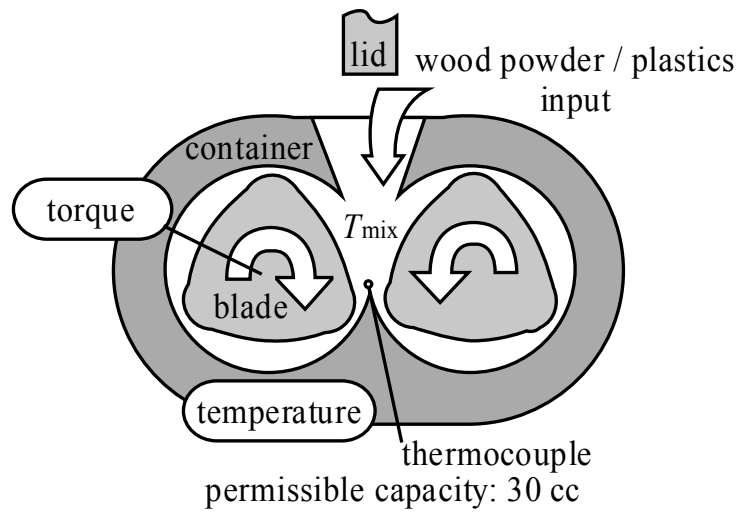

Fig. 2 Schematic view of mixing blender

\subsection{Mixing Procedure}

A mixing blender and a control machine, which are lineup products of Toyo Seiki Seisaku-syo Ltd. Lab-plast mill series 4C150, were used to compound the wood powder and the plastics. The schematic view of the mixing blender is shown in Fig. 2. In the fundamental experiment, a content of the wood and the plastics set at constant rate of 50:50 $\mathrm{wt} \%$, in which the plastics contain 5\% AMPP.

At a target temperature of the container in Fig.2, 20 grams mixtures of the wood powder and the plastics are filled and compounded in the container by rotating the blade in a $5 \mathrm{rpm}$ under the lid compression. After equalizing the thermocouple temperature in the mixtures to that of the container the blades revolve in the opposite direction at a constant rotation of 20 rpm under a closed system of the container and the lid for 10 minutes. During the rotation of the blades, a torque required is automatically monitored, while the temperature of the thermocouple gets feedback so as to make equal to that of the container temperature, and the thermocouple temperature defines the mixing temperature $T$ mix.

\subsection{Compression Process}

A wood powder compound of plastics after a mixing process is compressed by a flat metal mould under a constant pressure and a temperature of $5 \mathrm{MPa}$ at $170^{\circ} \mathrm{C}$ for 2 minutes 
to prepare a WPRC panel. For preventing vapor explosion, the WPRC panel is removed after cooling the mould temperature lower than $80^{\circ} \mathrm{C}$.

\section{Evaluations}

\subsection{Appearance}

To acquire appearance information of the WPRC panels, the overview and zoomed surface images are obtained by a KEYENCE digital microscope VHX-900. Also, a color difference and a brightness for standards are measured by a color meter, BYK Gardner. Average brightness $\mathrm{L}^{*}$ and color differences of $\mathrm{a}^{*}$ and $\mathrm{b}^{*}$ are obtained by three times measurements for a panel.

\subsection{Mechanical Properties}

Bulk density of the WPRC panels was calculated by a sizes and a weight after leaving the panels at constant condition of $20^{\circ} \mathrm{C}, 65 \% \mathrm{RH}$ for a while. That is, the panels will contain moisture and pores.

Tensile strength was measured for the tensile specimens, which were cut into $8 \mathrm{~mm}$ and $30 \mathrm{~mm}$ in gage width and length with a radius of $3.5 \mathrm{~mm}$ from a WPRC panel by a numerical controlled cutting machine. The tensile strength was decided from an average value of at least three times measurements in a constant tensile speed $1 \mathrm{~mm} /$ minute. Conditioning of the specimens is similar to that of bulk density. In this tensile test, elongation could not successfully be obtained, and only tensile strength, therefore, will be shown in this article.

\subsection{Size Stability}

As a size-stability of the WPRCs, a thickness change rate due to swelling and shrinkage of fractured tensile specimens was measured, in which a cyclic procedure of boiling water immersion for 1 hour and oven drying for 1hour were carried out twice. Each drying or wetting steps, the thickness were obtained, and the size stability was discussed based on the change in the thickness before and after immersion.

\section{Results and Discussion}

\subsection{Torque Required for Mixing}

Figure 3 (a) (b) shows the torque variations during 10 minutes mixing for (a) only plastic and (b) $45 \mathrm{wt} \%$ wood powder content to the plastics at various temperature of $T$ mix. It is found from Fig.3 (a) that the torques required for mixing decrease when the mixing temperature $T_{\text {mix }}$ is set higher.

Resultant value of $190{ }^{\circ} \mathrm{C}$ is almost a half compared with that of $170{ }^{\circ} \mathrm{C}$, and this behavior comes from the plastics deformability.

On the other hand, in Fig. 3 (b) there is an opposite tendency, in which the torques required for mixing increase when the mixing temperature $T$ mix is set higher. It is considered that the wood powder in the molten plastics acts as a resistance against compounding, and this increased or constant torques (seeing at $T_{\mathrm{mix}}=180,190$, and $200^{\circ} \mathrm{C}$ ) indicate interactions between wood powder and plastics. However, at $T$ mix of $170{ }^{\circ} \mathrm{C}$ the torque gradually deceases with time, and the mixing process does not seem to be successfully run. This tendency could be seen for all powder size used in the mixing process. 

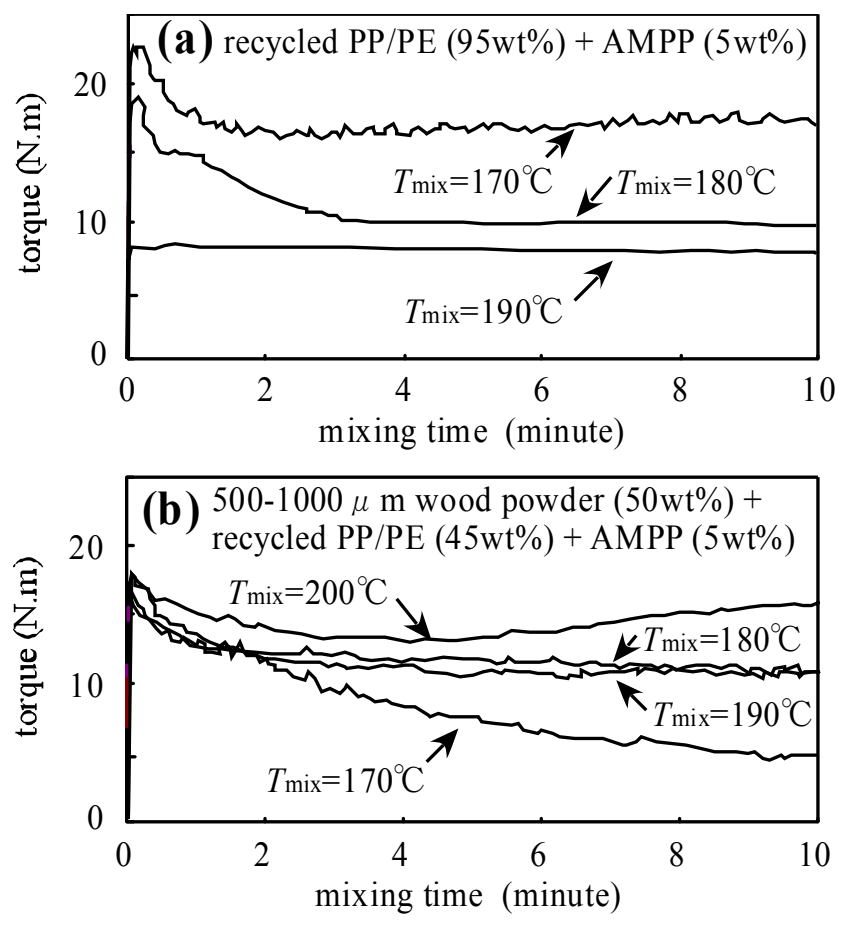

Fig. 3 Torque variation with 10 minutes mixing for (a) plastics and (b) wood powder compound

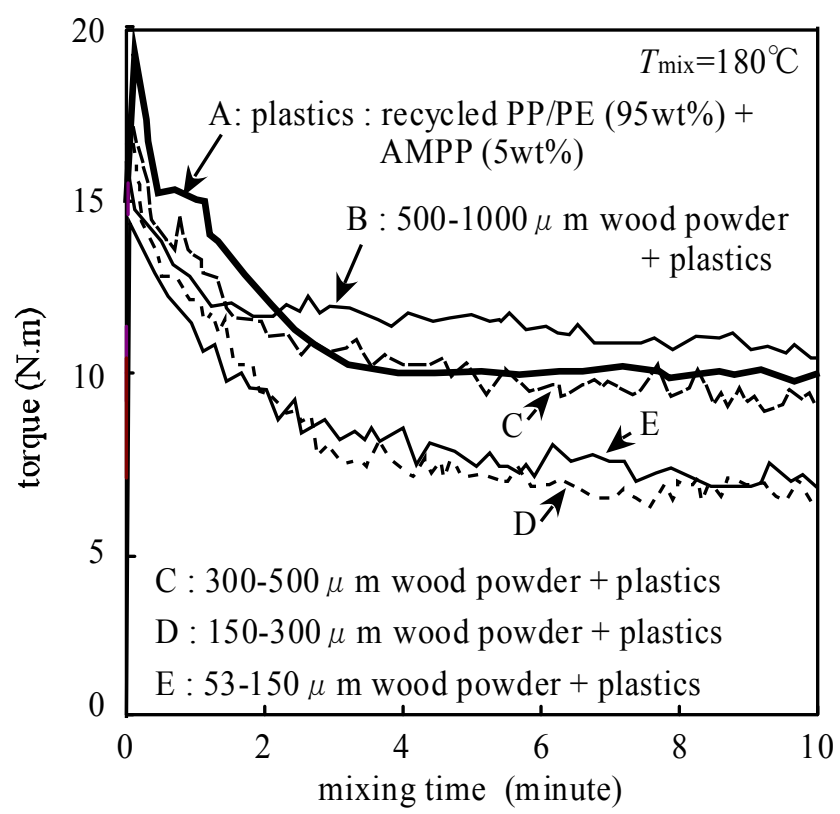

Fig. 4 Effects of the wood powder size on the torque variation during mixing processes at a constant temperature $180^{\circ} \mathrm{C}$

Figure 4 gives the effects of the wood powder size on the torque required for mixing processes at a constant $T$ mix of $180{ }^{\circ} \mathrm{C}$. The heavy-line (A) in the figure shows a result of the plastics only. Comparing the others line with this heavy one, a mixing resistance of wood powder and plastics can be found out. It is seen from the figure that $500-1000 \mu \mathrm{m}$ wood powder mixtures with plastics needs the maximum torque required for compounding, which is higher than that of the plastics only. And then, the mixtures with smaller wood powder show decreased torques, and it reaches minimum torque using $150-300 \mu \mathrm{m}$ or 53-150 $\mu \mathrm{m}$ wood powder. 


\subsection{WPRC Panels Appearance}

Figure 5 shows the overview appearance of the WPRC panels obtained by compressing various wood powder mixtures with plastics. Their compression conditions are constant but the mixing conditions are different. It is clearly distinguished that the color of the WPRC panels gets different by powder and mixing temperature conditions.

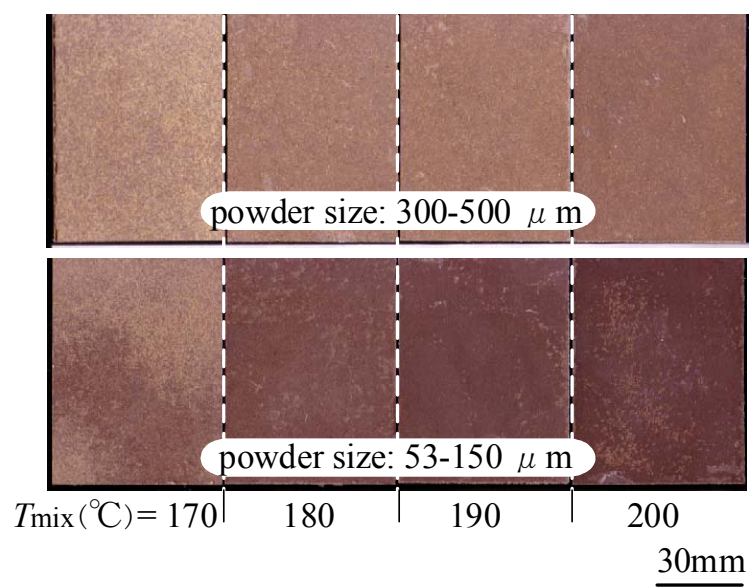

Fig. 5 Examples of WPRC panel prepared by hot-pressing of wood powder mixtures with plastics

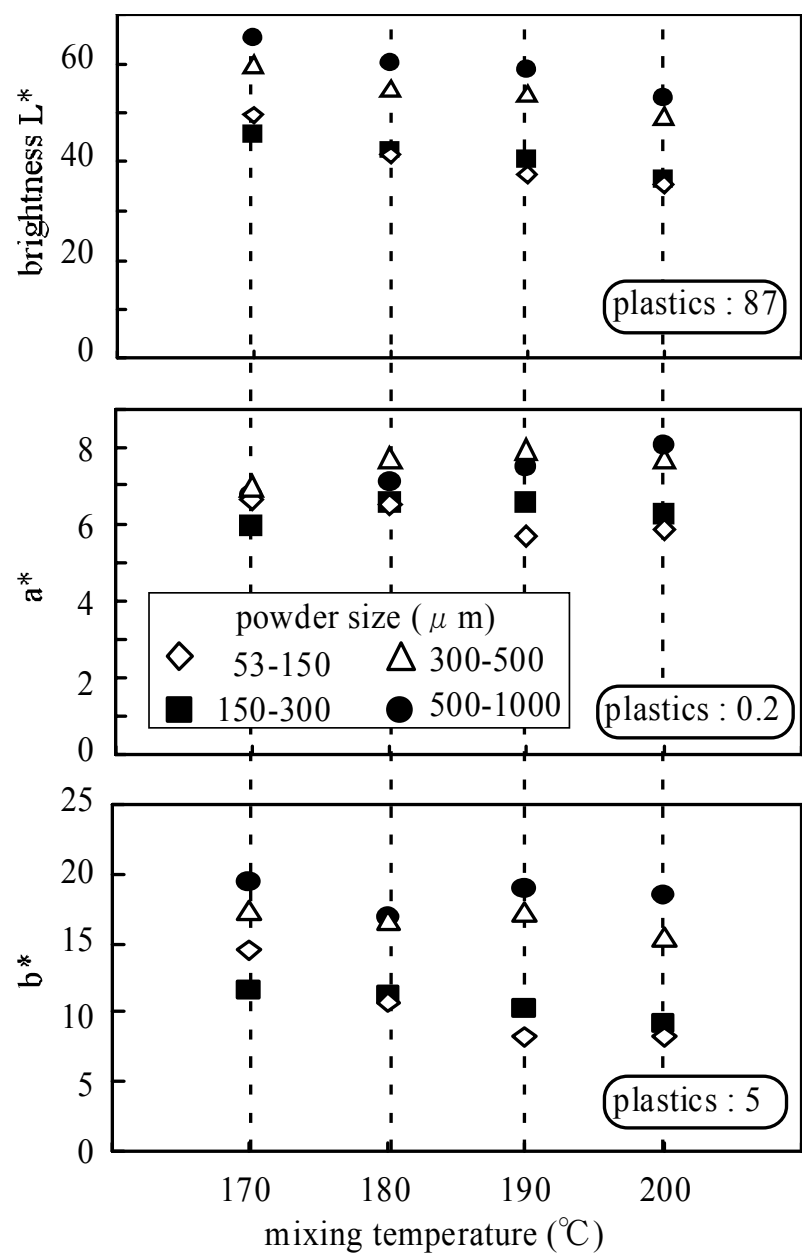

Fig. 6 Color information of WPRC panels prepared at various mixing temperatures 
Such color changes are explained by brightness $\mathrm{L}^{*}, \mathrm{a}^{*}$ and $\mathrm{b} *$ in Fig. 6 . The brightness $\mathrm{L}^{*}$ of the panels decreases when higher mixing temperature and smaller wood powders are applied. The $\mathrm{a}^{*}$ slightly increases with increasing mixing temperature for $300-1000 \mu \mathrm{m}$ wood powder mixtures with plastics, while that of the WPRC panels using $53-300 \mu \mathrm{m}$ powder mixtures shows almost constant or decreased values. The $b^{*}$ tends to decrease with increasing mixing temperature $T_{\text {mix }}$ for all panels. From these results, the brightness is the most influential factor on the WPRC color.

The zoomed views of the WPRC surfaces are given in Fig. 7. The difference of surface views depends on the mixing temperature $T$ mix of the wood powder mixture in the figure. It is seen that wood powder still exists on the surface of WPRCs at low mixing temperatures of 170 and $180^{\circ} \mathrm{C}$. Especially, at $170^{\circ} \mathrm{C}$ there is clearly-distinguished boundary between wood and plastics due to insufficient compounding. When increasing mixing temperature Tmix up to $190^{\circ} \mathrm{C}$, the boundary is hardly seen, and the plastics are dispersed uniformly on the surface of the panels. When the temperature $T$ mix reaches $200^{\circ} \mathrm{C}$, the wood powder is rarely seen on the surface and seems to exist underlying. Also, the color of plastics gets a little bit black which affects the appearance color shown in Fig. 5.

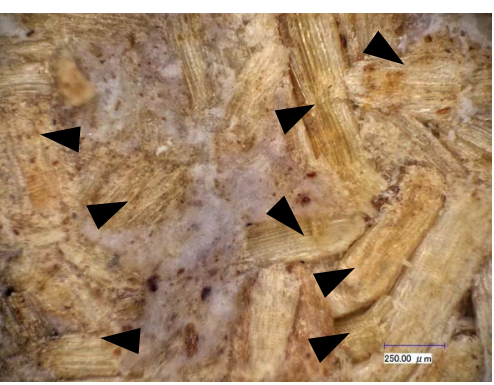

$T_{\text {mix }}=170^{\circ} \mathrm{C}$

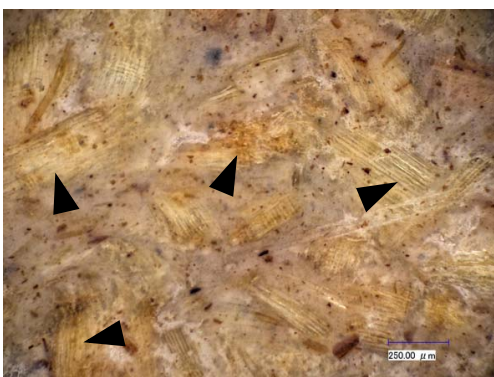

$T_{\text {mix }}=190^{\circ} \mathrm{C}$ powder size: $300-500 \mu \mathrm{m}$

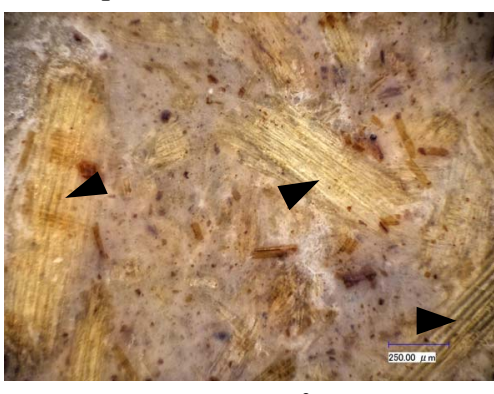

$T_{\operatorname{mix}}=180^{\circ} \mathrm{C}$

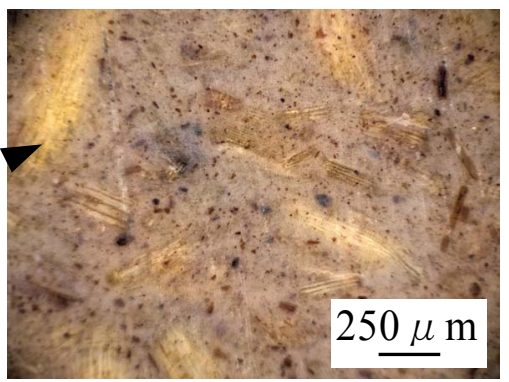

$T_{\operatorname{mix}}=200^{\circ} \mathrm{C}$

Fig. 7 Surface morphology of WPRC panels prepared at various mixing temperatures

The arrows $\boldsymbol{\Delta}$ show wood powders existing on the WPRC surface 


\subsection{Mechanical Properties}

Figure 8 shows the effects of the mixing temperature $T$ mix and the wood powder size on the bulk density of the WPRC panels. It is found out from the figure that the density increases when the mixing temperature $T$ mix of wood plastics mixture is increased up to $200^{\circ} \mathrm{C}$. However the influence of the wood powder size is not clear while at each mixing temperature $T_{\text {mix }}$ the density of the panel using $150-300 \mu \mathrm{m}$ shows maximum. Almost all panel densities are higher than that of plastics because wood shows more compressibility, and a resultant density of hot-compacted wood powder is considered to be as high as 1.2-1.3 $\mathrm{g} / \mathrm{cm}^{3}$.(8)

After measuring the bulk density, five pieces of tensile specimen were cut from a WPRC panel and the results are summarized in Fig. 9. The figure illustrates the effects of the wood powder size and the mixing temperature $T$ mix on the tensile strength of the WPRC. When using 53-150 $\mu \mathrm{m}$ wood powder mixtures with plastics compounded at $T$ mix $=$ $170^{\circ} \mathrm{C}$, specimens are all fractured at chucking portions due to poor strength. At higher $T$ mix up to $180^{\circ} \mathrm{C}$, there could not be seen obvious tendency of the powder size on the tensile strength. Above $T_{\text {mix }}=180^{\circ} \mathrm{C}$, a trend appears in which the tensile strength becomes larger when the wood plastics mixtures using smaller powder size are used for panels.

Figure 10 gives an example of fractured tensile specimen. In this study, all specimens including plastics only showed similar type of break, which is a kind of brittle fracture. As is seen in Fig. 11, using the wood plastics mixtures compounded at temperature as low as $T_{\text {mix }}=170^{\circ} \mathrm{C}$, clumped plastics can be found in the fractured surface. This means that compounding did not enough at low mixing temperature, and this leads to insufficient bonding between wood and plastics. On the other hand, boundary between wood and plastics is not clear and uniformly-distributed plastics are hardly seen at the temperature as high as $T_{\text {mix }}=200^{\circ} \mathrm{C}$.

From these results, mechanical properties like density and strength are affected by the wood powder size and its mixing temperature conditions, and under successful compound condition, the tensile strength of WPRC increased using smaller wood powder.

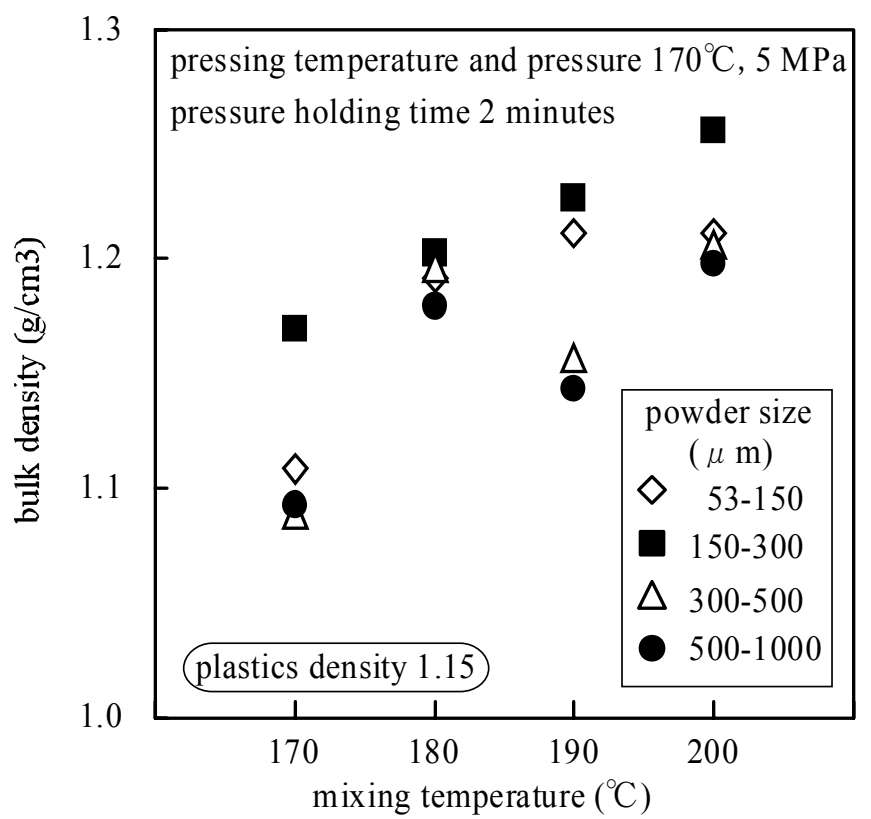

Fig. 8 Effects of mixing temperature and powder size on bulk density of WPRC panels 


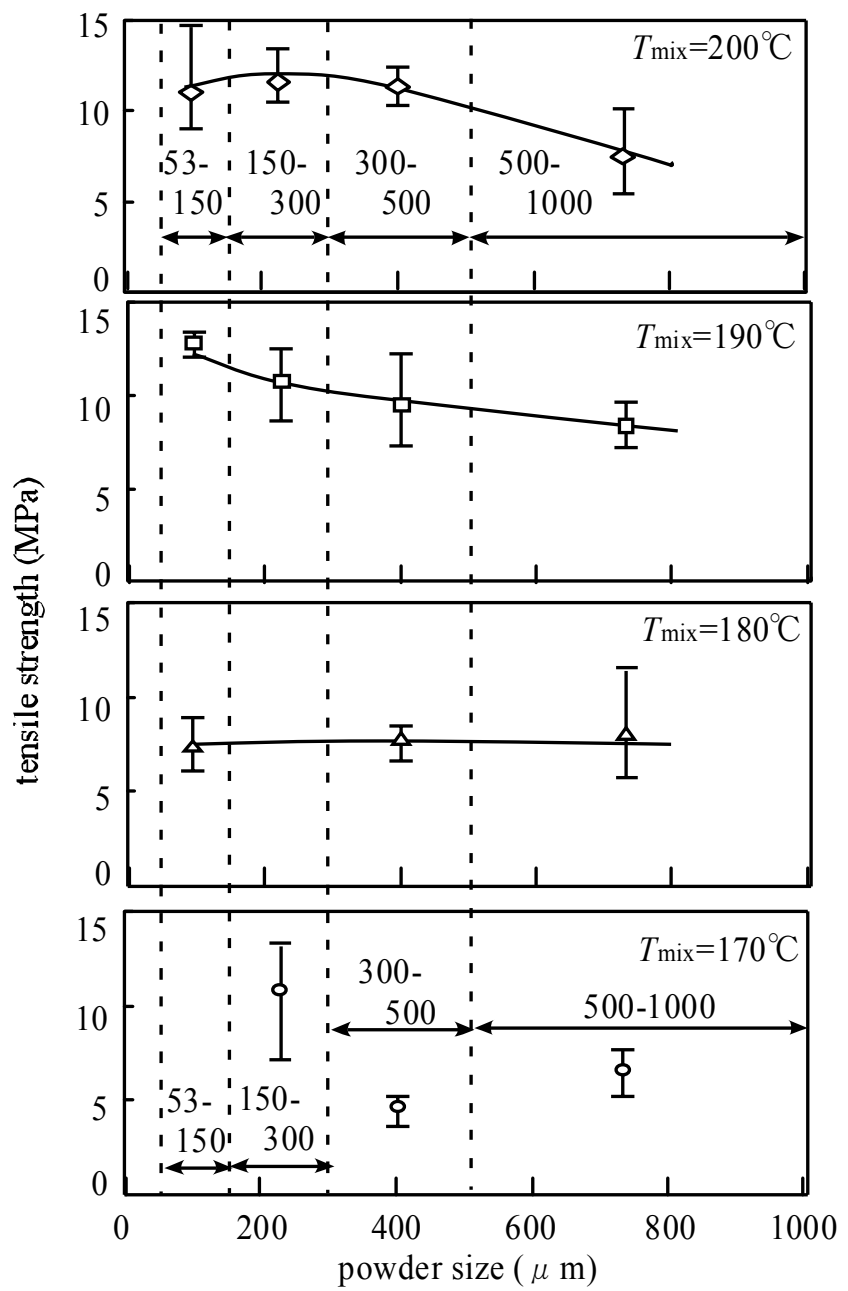

Fig. 9 Effects of mixing temperature and powder size on tensile strength of WPRC panels

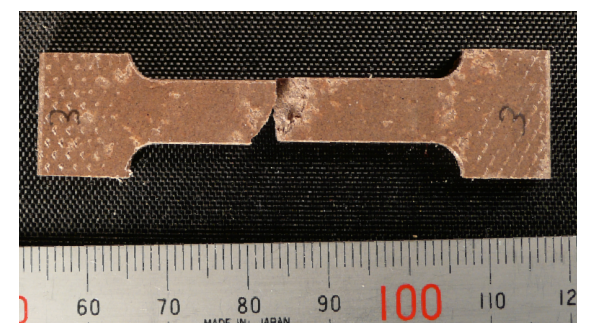

Fig. 10 An example of fractured tensile specimen
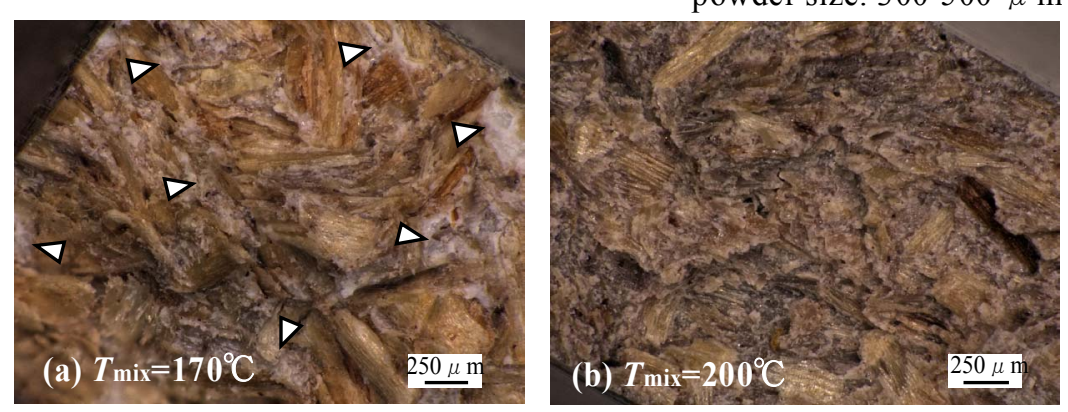

Fig. 11 Zoomed views of fractured surface of tensile specimen The arrows $\triangle$ show clumped plastics existing on the fractured surface of the WPRC 


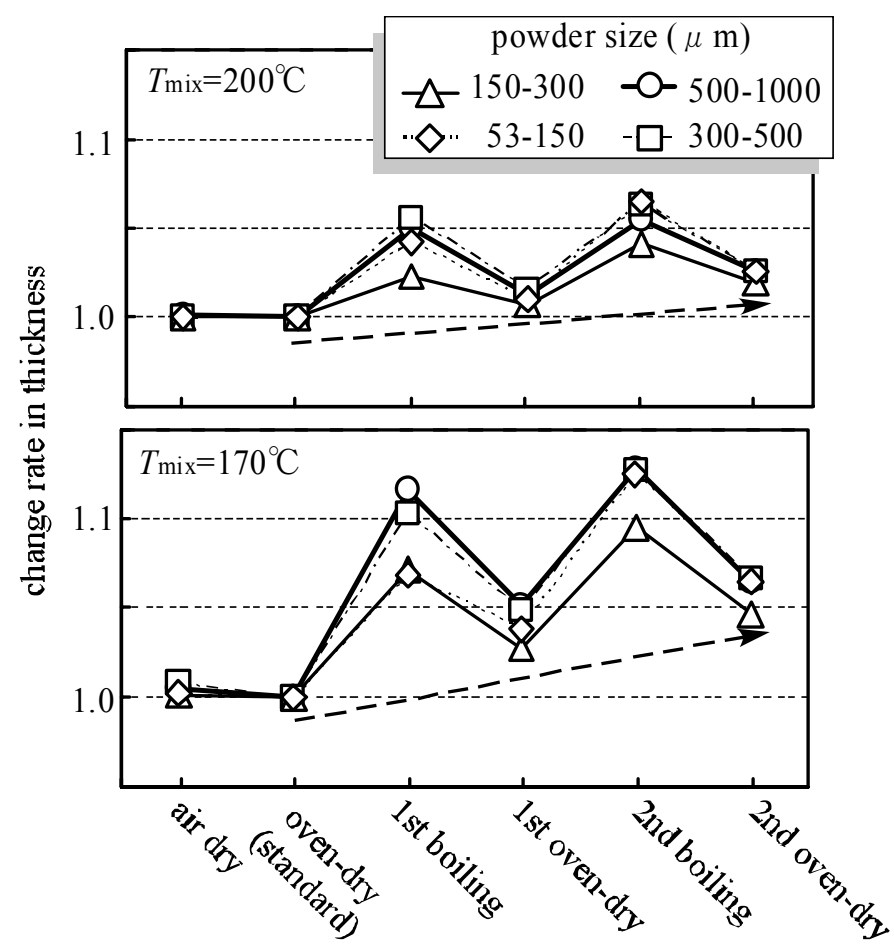

Fig. 12 Thickness changes due to swelling and shrinkage by size stability test

\subsection{Size Stability}

Thickness changes due to swelling and shrinkage by size stability test is illustrated in Fig. 12. WPRC prepared at mixing temperature $T_{\text {mix }}$ of $170^{\circ} \mathrm{C}$ shows great expansion in thickness by immersion in boiling water for $1 \mathrm{hr}$. At the first immersion in boiling water, the thickness expansion rate reaches $13 \%$ at maximum. Furthermore it slightly increases at second immersion after oven-drying, and this is obvious from baseline plotted by dashed line. There is similar trend for WPRC prepared at higher $T$ mix up to $200^{\circ} \mathrm{C}$, but the variation ranges as well as baseline slopes rather smaller. For WPRC applied $T$ mix of $200^{\circ} \mathrm{C}$, it shows $6 \%$ at maximum. The effect of powder size still is unclear while the size stability tends to improve using smaller powders. This thickness change seems to be caused by swelling and shrinkage of wood powder in WPRC and size recovery of wood powder, which is compressed in the production of WPRC panels, could result in the expansion of WPRC during dry-wet cycles. Therefore smaller powder in a WPRC leads to increase the interface between wood and plastics while bulk wood volume inducing swelling/shrinkage, consequently, is decreased. It is revealed that setting compound conditions including powder size and mixing temperature affect a size stability of WPRC.

\section{Conclusion}

To investigate the effects of the wood powder size and the mixing temperature in the compounding process of wood powder mixtures with plastics on the properties of wood plastic recycled composite (WPRC), a fundamental experiment was performed using four kinds of wood powder sizes and four mixing temperatures. Results show that the tensile strength of WPRC increases when the smaller wood powder is used as a raw material for wood/plastic compound under a successful mixing conditions. It is shown from thickness change rate that mixing temperature of wood/plastic compound affects a size stability of WPRC. However, to facilitate expansion of WPRC applications, further works like this 
study are necessary, in which reliability of this study is improved and only a few factors are subjected to research in the production condition of WPRCs.

\section{References}

1. Amanda Jacob, 2006, "WPC industry focuses on performance and cost", REINFORCED plastics, May, pp32-33.

2. Jennifer Markarian, 2005, "Wood-plastic composites: current trends in materials and processing”, Plastics Additives \& Compounding, September/October, pp 20-26.

3. JAPANESE INDUSTRIAL STANDARD, 2006, "Wood-plastic recycled composite JIS A 5741", Japanese Standards Association.

4. Elaham Hamidinia, Mehdi Tajvidi, 2006, "Mechanical properties of composites from sawdust and recycled plastics", Journal Applied Polymer Science, Vol. 100 (5), pp-3641-3645.

5. Saeed. K. Najafi, M. Tajvidi, E. Hamidina, 2007, "Effect of temperature, plastic type and virginity on the water uptake of sawdust/plastic composites", Holz als Roh-und Werkstoff, Vol. 65(5), pp377-382.

6. M. G. Salemane, A. S. Luyt, 2006, "Thermal and Mechanical Properties of Polypropylene-Wood Powder Composites”, Journal of Applied Polymer Science, Vol. 100, pp4173-4180.

7. M. KAZAYAWAKO, J.J. BALATINECZ, L.M.MATUANA, 1999, "Surface modification and adhesion mechanisms in woodfiber-polypropylene composites", Journal of Materials Science, Vol.34, pp6189-6199.

8. T. MiKi, K. Takeuchi, H. Sugimoto and K. Kanayama, 2007, "MATERIAL DEVELOPMENT FROM WOOD POWDER WITHOUT ADHESIVE BY VAPOR STEAMING COMPACTION PROCESS", Journal of Materials Processing Technology, Vol. 199(1), pp.396-401. 